\title{
¿HAY DERECHOS COMUNITARIOS?
}

\author{
¿No pueden ustedes decidir, \\ uno a uno, qué es lo correcto \\ y qué es lo incorrecto? \\ $¿$ Tienen ustedes que seguir \\ creyendo en grupos?
}

FAY WELDON

asta hace pocos años la lucha por los derechos civiles se libraba en nombre del liberalismo, buscando el otorgamiento de derechos individuales. La histórica decisión de la Corte Suprema norteamericana en el caso Brow vs. Board of Education consistió en otorgar a los individuos integrantes de la minoría negra los mismos derechos a la educación de los que ya disfrutaban los integrantes de la mayoría blanca, y que les habían sido negados en la decisión anterior que se adoptara en Plessy vs. Ferguson.

El liberalismo ha sido interpretado usualmente como una doctrina que presta especial atención a la protección de los integrantes de los grupos minoritarios. En tiempos cercanos, sin embargo, el movimiento comunitario ha cuestionado seriamente la capacidad del liberalismo para proteger a ciertos grupos minoritarios mediante la concesión de derechos individuales, y ha reclamado el otorgamiento de otro tipo de derechos: los derechos comunitarios.

Voy a analizar sucintamente la historia de la doctrina comunitaria y a señalar sus rasgos principales, para concentrarme luego específicamente en el tema de los derechos comunitarios y de su eventual adecuación para proteger los derechos de las minorías. No creo que la concesión de los llamados «derechos comunitarios» constituya la solución para proteger a las minorías amenazadas en su propia existencia y hay remedios mejores para ello, aunque no estén exentos de defectos.

Pero es conveniente aproximarse a esta conclusión de manera pausada.

\section{Los antecedentes de la tesis comunitaria}

Hay dos orígenes distintos del comunitarismo, los que se identifican con la filosofía aristotélica y la filosofía hegeliana, respectiva- 
mente. Aristóteles se proponía descubrir el bien a través del significado social de los roles que desempeñaban los individuos en la sociedad y de allí parte la versión comunitaria de MacIntyre, por ejemplo. Él piensa que la unidad de la vida humana se vuelve invisible cuando se postula una separación aguda entre el individuo y los roles que él desempeña. Su intento de rescatar el papel de los roles tiene por objeto el concebir nuevamente al yo como el portador de las virtudes aristotélicas ${ }^{1}$.

Hegel, a su vez, prefería a la comunidad frente al individuo, puesto que pensaba que la comunidad era el ámbito en el cual la ética alcanzaba su completitud ${ }^{2}$. Sería equivocado pensar, sin embargo, que estas dos vertientes comunitarias son incompatibles. Por el contrario, se ha mostrado que Hegel requería de la sociedad como ámbito para la plena realización de la libertad justamente porque él seguía a Aristóteles en la idea de que la sociedad constituía la realidad mínima auto-suficiente ${ }^{3}$. De modo que, de alguna forma, puede considerarse a Aristóteles como el inspirador central del comunitarismo.

Entre Aristóteles y Hegel, de toda forma, no puede obviarse la figura de Herder, quien privilegiaba las formas de vida en las que el individuo crece, prefiriéndolas al aislamiento cosmopolita. Sólo nos volvemos humanos -decía Herder- a través de la participación en la sociedad y en la tradición, puesto que no podemos tener ninguna comprensión de nosotros mismos, de lo que somos, y de lo que debemos ser, sino compartiendo formas comunes de vida. El papel de Herder en la reconstrucción del pensamiento comunitario es importante por la influencia que él ejerció sobre Hegel ${ }^{4}$.

Pero si bien es cierto que Aristóteles y Herder ejercieron una fuerte influencia en Hegel, y Hegel -a su vez- ejerció una fuerte influencia en Marx, no es cierto en cambio que el pensamiento marxista sea comunitario. Por el contrario, la teoría marxista piensa que todas las formas de identidad humana que se han realizado históricamente son episodios que esconden -antes que revelar- la esencia humana, por lo que la humanidad comunista será muy distinta de lo que la historia ha conocido y las adscripciones culturales que han otorgado sus identidades a los individuos reales serán borradas ${ }^{5}$.

\footnotetext{
190-191.

${ }^{1}$ Alasdair MacIntyre, After Virtue, Indiana, University of Notre Dame Press, 1981, págs.

${ }^{2}$ Charles Taylor, Hegel and Modern Society, Cambridge University Press, 1979, págs. 84-85.

${ }^{3}$ Taylor, cit., pág. 84.

${ }^{4}$ Charles Larmore, Patterns of Moral Complexity, Cambridge University Press, 1987, págs. 94 y 99.

${ }^{5}$ John Gray, Post-Liberalism, New York, Routledge, 1993, pág. 255.
} 


\section{Algunas caracterizaciones de la comunidad}

Las teorías comunitarias contemporáneas tienen diferencias entre ellas que alcanzan a la concepción misma de la comunidad. Todas ellas, sin embargo, parecen tener en común una idea fuerte de comunidad, entendida como algo más que un elemento de los planes de vida de sus miembros, y concebida -en cambio- como una característica constitutiva de la auto-comprensión de tales miembros ${ }^{6}$. Así, por ejemplo, una sociedad al estilo rawlsiano no alcanzaría a constituir una comunidad, puesto que sus integrantes sólo poseen un deseo de participar en esquemas cooperativos.

Los límites mismos de la comunidad no son fáciles de discernir, puesto que no coinciden necesariamente con los límites del estado: es obvio que un estado puede contener más de una comunidad cultural. Tal vez sea útil -por esta causa- separar los conceptos de estado (como una entidad caracterizada jurídicamente) y de nación (como una entidad caracterizada culturalmente) $)^{7}$.

Esto no concluye con la tarea, sin embargo, porque si la comunidad se equipara a la nación se asume ya un rasgo importante de aquella que dista de ser unánimemente aceptado: su tamaño. Algunos teóricos han postulado que las relaciones entre los miembros de una comunidad deben ser directas, sin mediación de líderes, representante o burócratas, y deben caracterizarse por la reciprocidad, por algún grado de ayuda mutua ${ }^{8}$. Si se aceptan estos rasgos la nación no es una comunidad, puesto que su tamaño es excesivo como para permitir que se prescinda de los representantes del estado o -incluso- que se practique la reciprocidad de un modo significativo.

Pero este concepto de comunidad -a su vez- ha sido considerado como muy estrecho, puesto que también puede hablarse de comunidad allí donde los miembros del grupo están unidos por un reconocimiento común o la cultura compartida, incluso cuando falta la familiaridad personal ${ }^{9}$.

Esto implica, por otra parte, abandonar el requisito de la reciprocidad como elemento constitutivo de las comunidades, al pág. 173.

${ }^{6}$ Michael J. Sandel, Liberalism and the Limits of Justice. Cambridge University Press, 1982, 249.

${ }^{7}$ Neil MacCormick, Legal Right and Social Democracy, Oxford, Clarendon Press, 1982, pág. $27-28$.

${ }^{8}$ Michael Taylor, Community, Anarchy and Liberty, Cambridge University Press, 1982, págs.

${ }^{9}$ David Miller, «The Ethical Significance of Nationality», Ethics, Vol. 98, número 4, pág. 654. 
menos entendido como fraternidad, como un vínculo emocional que liga a sus miembros ${ }^{10}$. El socialismo es la teoría más interesada en vincular a las comunidades con las naciones y el motivo de la vinculación así entendida es obvio: las naciones son las comunidades que interesan porque la comunidad se necesita para legitimar los procesos de justicia distributiva ${ }^{11}$.

\section{La teoría comunitaria y la redistribución del ingreso}

Los teóricos comunitarios suelen recordar que los esfuerzos serios de provisión comunitaria de bienes tienen un carácter redistributivo ${ }^{12}$. Los vínculos creados por la comunidad permiten un alto grado de redistribución del ingreso y la riqueza, puesto que sus miembros tienen un interés recíproco en su bienestar. En realidad hay una relación directa entre esos vínculos y el grado de redistribución, puesto que cuanto más fuerte sea el vínculo más igualitaria puede ser la distribución ${ }^{13}$. En la medida en que me identifico más fuertemente con mis conciudadanos, más me interesa su bienestar, y menos estoy dispuesto a aceptar que su nivel de vida sea muy inferior al mío.

La solidaridad desempeña aquí un papel decisivo y hay quienes piensan que ella se corporiza en la propiedad en común y en la distribución acorde con la necesidad, aún aceptando que ciertas cosas serían utilizadas especialmente por ciertas personas ${ }^{14}$.

Creo que los comunitarios se proponen dos objetivos respecto a la redistribución. El primero es obvio: redistribuir el ingreso y la riqueza de modo de eliminar las desigualdades más acentuadas. No se trata de un objetivo original y no se restringe -por cierto- a la teoría comunitaria. El segundo objetivo, en cambio, presenta más interés: en este caso el propósito consiste en limitar las consecuencias redistributivas, privándolas de todo alcance universalista y limitándolas a una comunidad. Un comunitario sostendría que en los Estados Unidos debería haber una mayor redistribución de la riqueza para llegar a un esquema más igualitario, pero también sostendría que ningún ciudadano norteamericano debería preocuparse por su riqueza vis-à-vis un ciudadano etíope, por ejemplo.

${ }^{10}$ David Miller, Market, State and Community, Oxford, Clarendon Press, 1989, pág. 250.

${ }^{11}$ David Miller, «In What Sense Must SocialismBe Communitarian?», Social Philosophy and Policy, Volumen 6, Issue 2, pág. 68.

${ }^{12}$ Michael Walzer, Spheres of Justice, New York, Basic Books, 1983, pág. 82.

${ }^{13}$ Miller, «In What Sense...», cit., pág. 59.

${ }^{14}$ Miller, Market, State and Community, cit., pág. 230. 
De allí la importancia que reviste el tamaño de la comunidad. Para que la redistribución produzca consecuencias políticas de importancia la comunidad debe identificarse con la nación, como pretende el pensamiento socialista. Las comunidades locales pueden redistribuir internamente, pero esta circunstancia no se puede extrapolar para sostener que la suma de estas distribuciones separadas producirán una adecuada redistribución total ${ }^{15}$. En este caso, sin embargo, la apelación a la solidaridad y a la reciprocidad pierde parte de su fuerza, la que es inversamente proporcional al tamaño de la comunidad. Se puede sostener que la comunidad requiere una cierta igualdad económica entre sus miembros ${ }^{16}$, pero cuanto más grande sea la comunidad menos percibirán sus miembros que esa igualdad es necesaria.

\section{La identidad personal en la tesis comunitaria}

El rasgo del liberalismo que más ha concentrado las críticas comunitarias es el de la concepción de las personas como seres individuales, cuyo bienestar es independiente de entidades tales como la familia, la comunidad, la tribu o la nación ${ }^{17}$. Es una crítica, en otras palabras, a la concepción que Charles Taylor denominó «atomismo» y que él cuestionó sosteniendo que la identidad de los individuos autónomos requiere una matriz social ${ }^{18}$.

En este aspecto Hegel se adelantó a los modernos comunitarios al desplazar el centro de gravedad del individuo a la comunidad: lo que somos como seres humanos lo somos sólo en una comunidad cultural, puesto que muchas de nuestras experiencias más importantes serían imposibles fuera de la sociedad ${ }^{19}$. En una concepción fuerte, hablar del sentido de comunidad es afirmar que los individuos conciben su identidad como definida -aunque sea parcialmente- por la comunidad de la que son parte; la comunidad no describe lo que los ciudadanos tienen, sino lo que los ciudadanos $\operatorname{son}^{20}$. El hecho de que la identidad personal está parcialmente constituida por las vinculaciones comunales se apreciaría en la cir-

${ }^{15}$ Miller, Market, State and Community, cit., pág. 237.

${ }^{16}$ Michael Taylor, cit., pág. 157.

${ }^{17}$ John Bigelow, Robert Pargetter and Robert Young, «Land, Well-Being and Compensation», Australasian Journal of Philosophy, Vol. 68, número 3, pág. 332.

${ }^{18}$ Charles Taylor, «Atomism», en Philosophy and the Human Sciences, Cambridge University Press, 1985, pág. 209.

${ }^{19}$ Charles Taylor, Hegel and Modern Society, cit., págs. 85 y 87.

${ }^{20}$ Sandel, cit., pág. 150. 
cunstancia de que la gente no se ve a sí misma sólo como individuos con intereses privados, sino como ligada a unidades sociales ${ }^{21}$.

En una concepción más débil valorar la comunidad es advertir que sólo nos convertimos en seres humanos completos, capaces de definir nuestra identidad, a través de un instrumento comunitario como el lenguaje, entendido en el sentido amplio de abarcar no sólo las palabras, sino también otros modos de expresión, tales como los «lenguajes» del arte y del gesto ${ }^{22}$. La identidad de un individuo depende en este caso de sus relaciones dialógicas con otros ${ }^{23}$. Pero reconocer la importancia del lenguaje, desde luego, no compromete necesariamente a apoyar una tesis comunitaria. Puede aceptarse que los seres humanos sólo adquieren un sentido de su propia individualidad como resultado de sus experiencias sociales dentro de ciertas comunidades ${ }^{24} \sin$ abandonar por eso la tesis liberal: al fin de cuentas el individuo liberal no es un Robinson Crusoe, ni un individuo que no habla ni hace gestos. Negar la verdad de la proposición de que el individuo es un ser desencarnado no compromete a aceptar la verdad de la proposición de que la identidad de los individuos está completamente determinada por su pertenencia a una única comunidad moral y a un único orden político ${ }^{25}$.

La crítica de Sandel a Rawls consiste en sostener que los individuos que prestan su acuerdo en la posición originaria rawlsiana existen sólo en la medida en que antes exista una comunidad. La exageración de Sandel reside en defender la idea de que el contexto social constituye completamente la identidad del individuo en lugar de aceptar que el yo está constituido sólo en forma parcial por su contexto y participa en la determinación de su propia identidad ${ }^{26}$. El yo liberal es un yo responsable de su cultura, por ejemplo ${ }^{27}$, aunque Sandel diría, desde luego, que sólo puede existir un yo comunitario.

Pero el gran problema que enfrentan los comunitarios es el

${ }^{21}$ Miller, Market, State and Community, cit.. pág. 234.

${ }^{22}$ Charles Taylor, Multiculturalism and «The Politics of Recognition», New Jersey, Princeton University Press, 1992, pág. 33.

${ }^{23}$ Charles Taylor, Multiculturalism..., cit., pág. 34.

${ }^{24}$ MacCormick, cit., pág. 247.

${ }^{25}$ Gray, cit., pág. 261.

${ }^{26}$ Robert K. Fullinwider, «Citizenship and Welfare», en Amy Gutmann(ed.), Democracy and the Welfare State, New Jersey, Princeton University Press, 1988, págs. 104 y 108.

${ }^{27}$ John R. Danley, «Liberalism, Aboriginal Rights, and Cultural Minorities», Philosophy and Public Affairs, Vol. 20, número 2, pág. 178. 
hecho de que muchas de las características consideradas como constitutivas de la identidad de un individuo tienden a cambiar en el tiempo, tal como la religión, para citar un solo ejemplo ${ }^{28}$. En este caso un mismo individuo puede encontrarse apoyando y criticando, en etapas sucesivas de su vida, ciertas ideas de las que se suponía que su identidad dependía.

Esta circunstancia se relaciona con otra dificultad que afecta a la tesis comunitaria: ¿cuál es el tipo de sociedad que defiende el comunitarismo y cuál es la actitud del individuo respecto de la sociedad?

\section{El individuo y la comunidad}

El problema de los comunitarios reside en el hecho de que ellos sostienen que la identidad del individuo está constituida -total o parcialmente- por su pertenencia a una comunidad. Los liberales no tienen este problema, por supuesto, ya que piensan que el individuo es responsable -total o parcialmente- de su cultura ${ }^{29}$. El liberalismo no sólo no impide, sino que a veces estimula un examen de la comunidad que puede conducir a grandes transformaciones culturales ${ }^{30}$, por lo que las comunidades, para el liberalismo, no son instituciones estáticas.

Contrastemos esta idea con el siguiente ejemplo: un gobierno argelino se ha establecido mediante una revolución que prometió respetar los derechos individuales. Una vez en el poder, sin embargo, el gobierno revolucionario viola sistemáticamente los derechos de los ciudadanos, justificándose mediante la apelación al argumento de que esta actitud es la única que se ajusta a las tradiciones argelinas y que es el único tipo de estado que los argelinos pueden considerar propio ${ }^{31}$. El gobierno sostiene, en otras palabras, que se debe vivir en Argelia bajo una dictadura porque así se vivió siempre, y porque la identidad de los ciudadanos está constituida en parte por su pertenencia a una comunidad de este tipo.

La primera objeción a este argumento es obvia: no tiene sentido decir que los individuos ejercen un derecho a expresar su cultura heredada cuando la forma de gobierno a la que están sometidos

${ }^{28}$ Leslie Green, «Consent and Community, en Paul Harris (ed.), On Political Obligation, London, Routledge, 1990, págs. 114-115.

${ }^{29}$ Danley, cit., pág. 176.

${ }^{30}$ Steven C. Rockefeller, «Comment», en Taylor, Multiculturalism..., cit., pág. 89.

${ }^{31}$ Michael Walzer, «The Moral Standing of States: A Response to Four Critics», Philosophy and Public Affairs, vol. 9, número 3, pág. 226. 
perpetúa una tradición de miseria, ignorancia e intimidación ${ }^{32}$, cuando es una forma de gobierno -en otras palabras- que viola sistemáticamente sus derechos. El asentimiento de los ciudadanos a un orden político determinado puede reflejar a veces un apoyo a ese orden, pero en muchos casos puede derivar también de una combinación de miedo, falta de interés y prudencia ${ }^{33}$, de modo tal que la cautela nunca resulta exagerada cuando se trata de examinar los motivos de la conducta acorde con lo que el gobierno prescribe. Recomendar que una práctica continúe en el futuro sólo porque proviene del pasado es un consejo propio de un conservadurismo extremo, que identifica a la sociedad buena con una sociedad de tradiciones $\operatorname{asentadas}^{34}$, en apariencia sin importar cuáles sean esas tradiciones. Sin que importe, por caso, que muchas prácticas culturales que prevalecen en ciertas sociedades fueron impuestas y definidas sólo por un sector de la población (hombres blancos de clase alta en los Estados Unidos, por ejemplo) ${ }^{35}$.

Ciertas prácticas comunitarias pueden ser dañinas y casi todos coincidirían en que ellas deberían ser interrumpidas: vendar los pies a las mujeres, inmolar a las viudas y practicar sacrificios humanos no son prácticas recomendables, aunque las propias víctimas -por seguir la tradición- las aprueben ${ }^{36}$. A la inversa, ciertas prácticas no pueden prohibirse -al menos desde el punto de vista liberal- sólo porque ofendan a la mayoría de los individuos de una comunidad, como es el caso de las prácticas homosexuales entre adultos que consienten $^{37}$. Pero, ¿pueden aceptarse estas críticas y atenderse estos consejos si se emplea una teoría de la identidad como la que los comunitarios postulan? Como puede apreciarse, el problema comunitario es muy claro: la identidad del individuo se identifica con su pertenencia a una comunidad, con la que él mantiene vínculos que no ha elegido y que no puede abandonar. Y -a su vez- la comunidad en cuestión puede muy bien no respetar los derechos individuales ${ }^{38}$. Si se

${ }^{32}$ Gerald Doppelt, «Statism without Foundations», Philosophy and Public Affairs, vol. 9. número 4, pág. 400.

${ }^{33}$ Joshua Cohen, «Review of Walzer "Spheres of Justice"», The Journal of Philosophy, August 1986, pág. 462.

${ }^{34}$ Amy Gutmann, «Communitarian Critics of Liberalism», Philosophy and Public Affairs, vol. 14, número 3, pág. 309.

${ }^{35}$ Will Kymlicka, «Liberal Individualism and Liberal Neutrality», Ethics, vol. 99, número 4, págs. 900-901.

${ }^{36}$ Janna Thompson, «Land Rights and Aboriginal Sovereignity», Australasian Journal of Philosophy, vol. 68, número 3, pág. 324. 88.

${ }^{37}$ Will Kymlicka, Liberalism, Community, and Culture, Oxford, Clarendon Pres, 1989, pág.

${ }^{38}$ Allen E. Buchanan, «Assesing the Communitarian Critique of Liberalism», Ethics. vol. 99, número 4, pág. 871 . 
acepta una tesis comunitaria en sentido fuerte quienes participen de una tradición no pueden explorar otras tradiciones ${ }^{39}$. Los individuos se subordinan a la ideología en la que viven, el espíritu de evaluación crítica se embota, y las únicas actividades y roles permisibles son aquellos que resultan compatibles con la ideología de la comunidad ${ }^{40}$. Este problema no se le presenta al liberalismo, puesto que el liberal cree que los individuos eligen la cultura a la que pertenecen.

Lo menos que podría exigirse a la tesis comunitaria es que reconociera en los ciudadanos una condición de racionalidad, que aceptara que ellos son capaces de someter las tradiciones de la sociedad a un escrutinio crítico $^{41}$. Pero, obviamente, la tesis comunitaria fuerte carece de recursos como para ir más allá de las nociones de virtud que la comunidad acepta de hecho ${ }^{42}$.

El problema central de los comunitarios, entonces, es el de encontrar un lugar en su teoría para evaluar a las comunidades a las que la gente pertenece ${ }^{43}$. Algunos comunitarios tratan de solucionar el problema liberando en parte al yo de sus vínculos con la comunidad: el yo encuentra su identidad moral a través de su pertenencia a comunidades, pero esto no implica que el yo tenga que aceptar las limitaciones morales de estas formas de comunidad. El yo, sin embargo, no puede aspirar a escapar por completo de la comunidad y entrar a un reino de máximas universales, que pertenecen al hombre como tal, y no como miembro de una comunidad ${ }^{44}$.

Pero para que la tesis comunitaria resulte aceptable hace falta algo más que esto: las comunidades que se aceptan deben ser de un 4, pág. 402.

${ }^{39}$ Julia Annas, «MacIntyre on Traditions», Philosophy and Public Affairs, vol. 18, número

${ }^{40}$ Michael Taylor, cit., pág. 163.

${ }^{41}$ Miller, Market, State and Community, cit., pág. 241. Rawls lo expresa de manera adecuada: sostenemos nuestra sociedad y nuestra cultura, y tenemos un conocimiento íntimo e inefable de ellas, incluso aunque mucho de ellas podamos cuestionar, sino rechazar. John Rawls, Political Liberalism, New York, Columbia University Press, 1993, pág. 222.

${ }^{42}$ Miller, «In What Sense...», cit., pág. 62.

${ }^{43}$ Green, cit., pág. 116. Quiero prevenir una posible confusión mostrando que el liberal no enfrenta el mismo problema. Desde luego que un liberal no puede criticar a una comunidad liberal desde adentro de su teoría, aunque puede evaluar a esa comunidad desde afuera de ella, puesto que su identidad no está constituida por su pertenencia a esa comunidad. Y el liberal, por supuesto, puede criticar desde adentro de su teoría a cualquier comunidad no liberal. Entonces, la única comunidad respecto de la cual el liberal tiene un problema de evaluación, por carecer de un punto de vista externo para practicarla, es la comunidad liberal, esto es, una comunidad con un contenido bien específico. El problema del comunitario es más grave, por cierto. Él no puede evaluar, desde su teoría, ninguna comunidad, sea cual fuera su contenido.

${ }^{44}$ MacIntyre, cit., págs. 205-206. 
cierto tipo. De un tipo tal como para permitir que se desarrollen las capacidades humanas y como para permitir el debate para clarificar y definir las alternativas disponibles ${ }^{45}$, donde la estructura cultural se reconozca como un contexto de elección ${ }^{46}$, de elección entre diversas alternativas que la comunidad respete. Esta idea excluye a algunas comunidades fundamentales. En realidad, algún lector avisado podría señalar que la única comunidad aceptada sería la comunidad liberal.

El teórico comunitario que defiende la versión fuerte de la tesis no puede compartir esta idea, desde luego, por la simple razón de que él piensa que la identidad de los individuos está constituida -al menos parcialmente- por su pertenencia a su comunidad, a cualquier comunidad a la que el individuo pertenece. Si se retiene la idea de una identidad así constituida la idea de acotar a las sociedades por su tipo debe rechazarse porque ella implica que sólo los individuos educados dentro de una comunidad que se aproxime a la liberal poseen una identidad ${ }^{47}$, lo que sería absurdo que un comunitario sostuviera.

Como se ve la tesis fuerte de los comunitarios no es fácil de defender. La vinculación del individuo con la sociedad es demasiado estrecha y conduce a perpetuar sociedades donde habría acuerdo en sostener que se cometen graves injusticias. Lo menos que puede hacer el comunitarismo es debilitar su tesis y reconocer que los individuos pueden meditar críticamente acerca de sus sociedades. De esta forma la tesis comunitaria débil queda a medio camino de la teoría liberal en materia de derechos. Porque nada garantiza que luego de esta meditación crítica los individuos -que no pueden liberarse por completo de las tradiciones de la comunidad ni adoptar una perspectiva universalista- opten por una comunidad que otorgue derechos que la tesis liberal considera fundamentales.

${ }^{45}$ Charles Taylor, «Atomism», cit., págs. 197 y 205.

${ }^{46}$ Kymlicka, Liberalism, Community, and Culture, cit., pág. 166.

${ }^{47}$ Dicho sea de paso la existencia de comunidades liberales plantea una eventual paradoja para la tesis comunitaria. Porque si se es comunitario, si se respeta la cultura de la comunidad, y si se cree que la pertenencia a la comunidad es parte de la identidad del individuo, entonces los comunitarios tienen que aceptar que los individuos nacidos en una sociedad liberal deben ser liberales, propiciando una suerte de «comunitarismo individualista». Los individuos en cuestión no debería intentar cambiar su sociedad liberal por una de otro tipo. ¿Aceptarían los comunitarios la idea de una sociedad liberal basada en estas premisas? 


\section{Derechos individuales y derechos comunitarios}

Como se advierte, hay diferencias fundamentales entre la doctrina liberal y la comunitaria acerca del modo de concebir el papel de los derechos. Las diferencias se agudizan, desde luego, cuando dentro de un mismo estado existe más de una comunidad, con diferentes rasgos culturales, o cuando existe una cultura pública -compartida por todos-, pero existen también diversas culturas privadas ${ }^{48}$. Cuando la comunidad no es homogénea y dentro de una misma sociedad coexisten distintas formas de creencias y de comportamiento estamos frente a un caso de diversidad cultural ${ }^{49}$.

Una respuesta liberal posible frente a los casos de diversidad cultural consiste en eliminar las desigualdades y convertir a las leyes en instrumentos ciegos a la raza y al color $^{50}$. El liberalismo no acepta el reconocimiento de grupos religiosos, raciales o lingüísticos como entidades corporativas que deban ser sujetos de derechos especiales ${ }^{51}$. El estado liberal, simplemente, se limita a garantizar el cumplimiento de los derechos individuales básicos -tanto civiles cuando políticos- que constituyen el contenido de cualquier bill of rights ${ }^{52}$. Esta posición, desde luego, equivale a adherir a la tesis atomista que he mencionado antes y que constituye el objeto de la crítica comunitaria. Los liberales aceptan el principio según el cual es obligatorio para los individuos pertenecer a una sociedad y contribuir a sostenerla, dice Taylor ${ }^{53}$.

El sistema de protección liberal no garantiza -ciertamente- la subsistencia de todas las comunidades. Cada tradición cultural tendrá una libertad igual para desarrollarse y ninguna resultará favorecida en particular. Aquellas, entonces, que requieran para sobrevivir de una ayuda gubernamental preferente es posible que no sobrevivan ${ }^{54}$. ¿Es éste un rasgo negativo de la teoría liberal? Un argumento para rechazar esta afirmación consiste en sostener que las comunidades que no resisten la competencia no merecen sobrevivir. Otro argumento usual reside en afirmar que si la comunidad representa un papel muy importante en la vida de sus miembros, ellos lograrán que sobreviva. Sin evaluar estos argumentos, lo cier-

${ }^{48}$ Miller, Market, State and Community, cit., pág. 244.

${ }^{49}$ David Miller, «Socialism and Toleration», en Susan Mendus (ed.), Justifying Toleration, Cambridge University Press, 1988, págs. 243-244.

${ }^{50}$ Danley, cit., pág. 170.

${ }^{51}$ Kymlicka, «Liberal Individualism and Liberal Neutrality», cit., pág. 904.

${ }^{52}$ Buchanan, cit., pág. 854.

${ }^{53}$ Charles Taylor, «Atomism», cit., pág. 53.

${ }^{54}$ Gray, cit., págs. 265 y 267. 
to es que la doctrina liberal -como dato empírico- tiende a producir una cultura única para toda la sociedad y concluye asimilando a esa cultura a las comunidades culturalmente minoritarias ${ }^{55}$.

La diferencia entre liberales y comunitarios en este aspecto puede ser mostrada del siguiente modo: los comunitarios perciben a los diferentes grupos culturales como permanentes, como determinando en parte la identidad del individuo. Los liberales, por su parte, entienden la pertenencia a un grupo como un problema -al menos parcial- de preferencias personales, y ven a los grupos mismos como entidades transitorias que terminarán -eventualmente- asimilándose a la sociedad común.

Los liberales piensan que si bien un individuo no es responsable por la circunstancia de haber nacido en una tribu aborigen -por ejemplo- si lo es por su respuesta ante esa circunstancia. El individuo en cuestión todavía puede elegir entre vivir su vida dentro de la cultura en la que nació o asimilarse a otro cultura. La asimilación a otra cultura no produce daño alguno a los individuos en tanto se cumplan dos condiciones que los liberales garantizan: a) que la asimilación sea voluntaria y no forzada, y b) que los individuos asimilados no sean considerados como ciudadanos de segunda clase ${ }^{56}$. La concesión de derechos individuales es lo que garantiza el cumplimiento de estas dos condiciones. Y, en realidad, el atractivo de los derechos individuales es tan grande que incluso la doctrina comunitaria no aspira a que ellos desaparezcan, sino sólo a cambiarles su carácter, convirtiéndolos en este caso en instrumento de algún propósito de la comunidad ${ }^{57}$. Esta afirmación es verdadera al menos respecto del comunitario moderado, que reconoce la existencia de derechos individuales, aunque se diferencia del liberal al aceptar que ellos pueden ser limitados apelando al bien de la comunidad. Tal vez un comunitario radical, sin embargo, rechazaría cualquier derecho individual y los sustituiría por lo que él llama derechos grupales ${ }^{58}$. Contrastando con esta actitud del comunitario moderado, el teórico liberal es hostil a la concesión de derechos colectivos, los que identifica con doctrinas autoritarias, incluso de genealogía fascista ${ }^{59}$. Luego veremos cuál es el verdadero carácter que revisten estos supuestos derechos colectivos.

${ }^{55}$ Kymlicka, Liberalism, Community, and Culture, cit., pág. 152.

${ }^{56}$ Danley, cit., págs. 177, 179 y 181.

${ }^{57}$ George Kateb, «Democratic Individuality and the Meaning of Rights», en Nancy L. Rosenblum(ed.), Liberalism and the Moral Life, Cambridge, Mass., Harvard University Press, 1989, pág. 201.

${ }^{58}$ Buchanan, cit., pág. 855 .

${ }^{59}$ Michael McDonald, «Should Communities Have Rights?», The Canadian Journal of Law and Jurisprudence, vol. IV, número 2, pág. 227. 
Aunque la idea de los derechos individuales es bien conocida tal vez no lo sea tanto la idea misma de los derechos colectivos, por lo que conviene detenerse un momento aquí. Una medida determinada cuenta como un derecho colectivo si ella especifica que la propia comunidad ejerce un cierto poder ${ }^{60}$ como consecuencia de ese derecho. El grupo mismo es detentador de derechos y actúa como su portador frente a varios portadores de obligaciones $^{61}$.

Quienes argumentan en favor de los derechos colectivos sostienen que no puede resolverse el problema de la discriminación grupal -especialmente el de la discriminación pasada- apelando a derechos individuales, puesto que con derechos individuales es sólo el individuo que acciona quien recibe una satisfacción ${ }^{62}$. Los negros norteamericanos de la actualidad no podrían invocar los males causados por la esclavitud a sus antepasados, ni podrían los indios norteamericanos actuales quejarse por las violaciones de derechos de la conquista del oeste. Tampoco la concesión de derechos individuales remedia aquello que los comunitarios consideran un mal: la asimilación de las culturas minoritarias y la resultante homogeneización cultural. Los comunitarios acusan a los liberales de limitarse a proponer programas para eliminar la pobreza, para asimilar a los indios o para llevar un modo de vida urbano al campo. Pero estas propuestas consisten sólo en dar más de lo mismo, dicen los comunitarios. En realidad agravan incluso el problema, puesto que la homogeneización ha socavado a las comunidades sin poner nada en su lugar ${ }^{63}$.

Los derechos grupales, según los comunitarios, protegen intereses que no pueden ser protegidos de otra manera, puesto que son intereses colectivos o sociales, tal como los intereses de los seres humanos de pertenecer a -o identificarse- con un grupo cultural ${ }^{64}$. Y esos intereses deben ser protegidos por la comunidad, y no por el ejercicio de derechos individuales por parte de sus miembros, puesto que no son los intereses de los miembros los que están en juego, sino los intereses de la comunidad ${ }^{65}$. Estos derechos grupales se proponen lograr un espacio en el cual predominan las reglas del grupo y no las de la sociedad más amplia que se supone que el

${ }^{60}$ Kymlicka, Liberalism, Community, and Culture, cit., pág. 139.

${ }^{61}$ McDonald, «Should Communities Have Rights?», cit., pág. 220.

${ }^{62}$ Glazer, cit., pág. 88.

${ }^{63}$ Charles Taylor, Hegel and Modern Society, cit., págs. 114-115.

${ }^{64}$ McDonald, «Should Communities Have Rights?», cit., pág. 229.

${ }^{65}$ McDonald, «Should Communities Have Rights?», cit., pág. 232. Creo que no necesito enfatizar la raíz hegeliana de esta concepción, que considera posible la existencia de intereses societarios independientes de los intereses de los integrantes de la sociedad. 
grupo integra, especialmente en áreas tales como la educación, las comunicaciones y la forma de las instituciones políticas, cuestiones consideradas cruciales para la supervivencia del grupo ${ }^{66}$. La concesión de estos derechos significa aceptar la política de la diferencia, en la que se reconoce la identidad única del grupo. El tratamiento diferencial consiste en conceder ciertos derechos especiales al grupo para permitirle preservar su identidad cultural $^{67}$, la que resultaría amenazada si su protección quedara librada a los derechos individuales.

\section{Un problema específico}

Conocido ya el alcance de las categorías de derechos individuales y de derechos comunitarios corresponde aplicarlas ahora a un caso concreto: la situación de una comunidad minoritaria cuya subsistencia está amenazada y que puede concluir asimilada a la cultura mayoritaria. Se trata de los aborígenes canadienses, que podrían concluir adoptando el modo de vida de los canadienses blancos, francófonos o anglófonos, perdiendo así su identidad cultural. La población india nativa vive en Canadá en reservas segregadas, sujeta a una legislación que discrimina entre indios y no indios. Los indios tienen restricciones respecto de su capacidad de usar la tierra y prohibición absoluta de venderla. Los no indios -a su vez tienen restringidos sus derechos de movilidad, residencia y voto ${ }^{68}$. Esta diferencia en el trato se justifica invocando la necesidad de respetar a los indios como indios, como miembros de una comunidad cultural distinta, y no como canadienses, como ciudadanos de una comunidad política común. ${ }^{69} \mathrm{Si}$ la tierra de los indios se dividiera entre los miembros individuales de la tribu y ellos fueran libres de venderla según su voluntad, en una generación la tierra podría estar en manos de urbanizadores blancos que cambiarían el modo de vida de la comunidad. Ya no existirían, por ejemplo, las

${ }^{66}$ Michael McDonald, «Liberalism, Community, and Culture», 42 University of Toronto Law Journal 113, págs. 124-125.

${ }^{67}$ Charles Taylor, Multiculturalism... cit., pág. 142.

${ }^{68}$ Kymlicka, Liberalism, Community and Culture, cit., pág. 142. Estoy adoptando aquí -adrede- la posición más favorable al comunitarismo, la que consiste en suponer que en cada comunidad sólo hay un modo de vida. Esta posición es, falsa en determinados casos: los mormones tienen actitudes divergentes frente a la poligamia y los judíos ortodoxos la tienen respecto del estudio del Talmud por parte de las mujeres. Cfr. Amy Gutmann, «The Challenge of Multiculturalism in Political Ethics», Philosophy and Public Affairs, vol. 22, número 3, págs. 175-176 y 188-189.

${ }^{69}$ Kymlicka, Liberalism, Community, and Culture, cit., pág. 51. 
opciones de ser cazador, o brujo ${ }^{70}$, y los niños aborígenes verían como normal el modo de vida occidentalizado y no en el modo de vida tradicional de su comunidad ${ }^{71}$. De modo que la preferencia de los indios (o, al menos, de parte de ellos) por la segregación no sería reflejada en el funcionamiento del mercado.

Esta consecuencia no se debería a ningún defecto peculiar de los aborígenes. Ocurre, simplemente, que ellos están sujetos a una ley extraña y no tienen control sobre los individuos que ingresan a su territorio. Los comunitarios sostienen que invadir el territorio de otras personas no sólo amenaza sus propiedades, sino también su vida común y sus pautas culturales. En el caso de los indios habría una clara conexión entre la pérdida de la soberanía y la pérdida de la capacidad para mantener su vida común ${ }^{72}$, con el agravante de que cuando una comunidad se destruye es para siempre, pues no puede ser reconstruida de nuevo ${ }^{73}$.

El problema no se confina a los indios, ciertamente. Los habitantes de Quebec, que ven su cultura amenazada por el predominio anglófono en Canadá, demandan el derecho de restringir el ingreso de otros canadienses a su territorio ${ }^{74}$. Por lo pronto, ya Quebec ha promulgado ciertas leyes en el campo del lenguaje: ni los francófonos ni los inmigrantes pueden enviar a sus hijos a escuelas angloparlantes y las empresas que tengan más de cincuenta empleados deben ser dirigidas en francés ${ }^{75}$.

Sin embargo, y pese a que la principal preocupación de estas comunidades reside en la inmigración, es difícil proponer como solución el aislamiento de las mismas, dejándolas al margen de todo contacto con otras civilizaciones, ${ }^{76}$ y de hecho no es ésta la solución que se propone. ¿Qué efectos produciría -entonces- el adoptar una solución ortodoxamente liberal para este problema? La política liberal no alienta de modo específico a las comunidades, pero las preserva -con su política de derechos individuales- en los casos en que ya existen, o en los que un número suficiente de individuos desea constituirlas. Obviamente no alienta su florecimiento, puesto

${ }^{70}$ Danley, cit., pág. 181.

${ }^{71}$ McDonald, «Liberalism, Community, and Culture», cit., págs. 128-129.

${ }^{72}$ Thompson, cit., págs. 316 y 320 . En el caso de Australia el mercado nunca funcionó, por la sencilla razón de que los colonizadores despojaron a los indígenas de sus tierras.

${ }^{73}$ McDonald, «Should Communities Have Rights?», cit., pág. 230.

${ }^{74}$ Kymlicka, Liberalism, Community, and Culture, cit., pág. 225. No es casualidad, como puede verse, que el comunitarismo haya tenido tanta difusión en Canadá.

${ }^{75}$ Charles Taylor, Multiculturalism.., cit., págs. 52-53.

${ }^{76}$ Thompson, cit., págs. 325-326. 
que la política liberal practica en este aspecto la neutralidad. En realidad los derechos individuales liberales permiten el cambio pacífico dentro de las comunidades ${ }^{77}$, pero los comunitarios considerarían este rasgo más como un defecto que como una virtud.

Desde el punto de vista liberal, el Gobierno respeta la diversidad de las tradiciones culturales, y permite la existencia de culturas rivales, e incluso compatibles. Pero no garantiza, con subsidios ni de ninguna otra manera, la institucionalización de tradiciones o de modos de vida ${ }^{78}$, puesto que no es esa su tarea.

Para aquellos que asignan un valor decisivo a la existencia continuada de las comunidades esta solución del liberalismo tradicional resulta insatisfactoria, por lo que se han propuesto otros remedios para este problema.

\section{Dos soluciones que apelan a derechos comunitarios}

El primero de tales remedios pertenece a Will Kymlicka y se caracteriza por mantener la estructura liberal a la par que incorpora a ella derechos comunitarios. La idea comienza sosteniendo la importancia que reviste la pertenencia cultural desde el punto de vista político, una vez que se ha aceptado el deber positivo del estado de proteger las condiciones culturales que permiten la elección autónoma ${ }^{79}$.

Frente a esta situación tradicionalmente han aparecido dos respuestas. La liberal consiste en otorgar poder a los grupos desaventajados de modo que éstos puedan desarrollar las prácticas comunes que promueven sus fines, lo cual -sin embargo- no asegura la efectiva promoción de tales fines. La comunitaria -a su vez- postula la existencia de fines compartidos que sirven como base para una política del bien común, fines que pueden ser encontrados en los roles y prácticas históricas; pero esta postura olvida que esos fines sólo fueron definidos por una pequeña porción de la sociedad ${ }^{80}$. Ninguna de las soluciones tradicionales, entonces resulta por completo satisfactoria.

Los derechos de las culturas minoritarias aparecen en el momento en que se reconoce la circunstancia de que la gente pertenece a distintas culturas y tiene un interés legítimo en asegurar la continuación de su propia cultura. Los derechos comunitarios se justificarían, de este modo, por su capacidad para permitir a las culturas minoritarias el desarrollar su propia vida cultural, capaci-

\footnotetext{
${ }^{77}$ Buchanan, cit., págs. 865-866 y 872.

${ }^{78}$ Gray, cit., pág. 266.

${ }^{79}$ Kymlicka, «Liberal Individualism and Liberal Neutrality», cit., pág. 904.

${ }^{80}$ Kymlicka, Liberalism, Community and Culture, cit., pág. 87.
} 
dad que resultaría insuficientemente protegida, recurriendo a derechos individuales ${ }^{81}$.

La dificultad que aparece ahora consiste en armonizar la existencia de estos derechos comunitarios con la doctrina liberal, puesto que a primera vista no hay lugar para la idea de derechos colectivos dentro de la ontología del liberalismo: para el liberalismo la comunidad no tiene pretensiones propias. Por eso mismo los liberales canadienses consideraron -yo creo que con corrección- que su teoría era incompatible con la asignación de derechos colectivos a la cultura minoritaria aborigen ${ }^{82}$. ¿Cómo puede solucionarse esta dificultad, entonces? Reconociendo que los miembros de las comunidades culturales minoritarias enfrentan problemas especiales con respecto al bien de la pertenencia cultural, y que esta desventaja requiere el otorgamiento de derechos minoritarios. No porque esas comunidades tengan algún tipo especial de status -desde luego-, sino porque sólo a través de una estructura cultural segura los individuos pueden conocer las opciones disponibles y examinar su valor. Si la pertenencia cultural es importante para perseguir nuestro interés en llevar una vida buena, entonces, piensa Kymlicka, tener en cuenta esa pertenencia forma parte del tener igual consideración por los intereses de cada miembro de la comunidad ${ }^{83}$. Claro está que podría argumentarse que las elecciones aborígenes, tal como las de los demás individuos, deberían estar sometidas a las exigencias del mercado. Si los aborígenes optan por un estilo de vida caro, que requiere la posesión de una gran cantidad de tierra que debe dejarse sin desarrollar, ¿por qué no pujan por ella en el mercado? Un intento de respuesta surge de considerar las circunstancias desiguales que los aborígenes enfrentan. La existencia misma de la comunidad cultural aborigen depende de las decisiones de la mayoría no aborigen que la rodea, por lo que ellos deben gastar sus recursos en asegurar su pertenencia cultural, mientras los no aborígenes la tienen asegurada gratis. Las medidas especiales requeridas por los aborígenes servirían sólo para eliminar una ventaja que los no aborígenes ya tienen antes de elegir ${ }^{84}$. Y -finalmente- la comunidad que se protege de esta manera no restringe la individualidad: por el contrario, es la pertenencia a una comunidad cultural la que permite la libertad individual y las elecciones significativas respecto del modo de conducir nuestra vida ${ }^{85}$.

${ }^{81}$ Kymlicka, Liberalism, Community, and Culture, cit., págs. 136-137.

${ }^{82}$ Kymlicka, Liberalism, Community, and Culture, cit., págs. 140 y 144.

${ }^{83}$ Kymlicka, Liberalism, Community, and Culture, cit., págs. 162, 165 y 167-168.

${ }^{84}$ Kymlicka. Liberalism, Community, and Culture, cit., págs. 185 y 189.

${ }^{85}$ Kymlicka. Liberalism, Community, and Culture, cit., pág. 208. 
¿Qué puede decirse de este intento de Kymlicka de compatibilizar al liberalismo con la concesión de derechos comunitarios? Ante todo -sin duda- que es una compatibilización parcial. Sólo se justifica proteger mediante este tipo de derechos a las comunidades que defienden la libertad de elección y valoran la autonomía: en otras palabras, a las comunidades liberales. Una comunidad fundamentalista no podría requerir su protección mediante este tipo de derechos, por lo que tendría razón McDonald en afirmar que Kymlicka argumenta en favor de la hegemonía de la cultura liberal ${ }^{86}$.

Por otra parte la idea de Kymlicka se apoya en la afirmación de que la posición en la que se encuentran los aborígenes es un producto de las circunstancias y no un producto de la elección ${ }^{87}$, y su argumento depende entonces de que pueda mostrarse que la cultura de un individuo es una circunstancia de la que él no es responsable. Pero aunque los aborígenes tengan sentimientos muy fuertes respecto de su identidad cultural pueden sin embargo construir nuevas relaciones e instituciones culturales ${ }^{88}$, como lo demuestra, por cierto, la gran cantidad de aborígenes que han optado con éxito por asimilarse a la cultura occidental. De modo que no sería correcto comparar la pertenencia a una cultura con una deficiencia física, por ejemplo, porque los individuos con deficiencias físicas preferirían dejarlas de lado si pudieran hacerlo y su problema reside en que no pueden. Mientras, por el contrario, los miembros de las culturas minoritarias no desean abandonar su pertenencia cultural, aunque podrían hacerlo. Podrían hacerlo en la medida en que un individuo que es criado dentro de una cultura llega a un momento de su vida en el que es capaz de elegir entre retenerla o abandonarla, por lo que retener la pertenencia cultural se acerca a una elección ${ }^{89}$.

Esta última crítica a la posición de Kymlicka le es dirigida desde el interior de la teoría liberal. Desde el punto de vista comunitario la crítica que se le dirige trata de mostrar que su concepción es insuficiente para asegurar la supervivencia de la cultura minoritaria. Protege a la gente que existe, pero no a las generaciones futuras, y esta última protección sería lo que está en juego ${ }^{90}$. El intento conciliador de Kymlicka parece no haber convencido entonces ni a liberales ni a comunitarios.

\footnotetext{
${ }^{86}$ McDonald, «Liberalism, Community, and Culture», cit., pág. 127.

${ }^{87}$ Kymlicka, Liberalism, Community, and Culture, cit., pág. 191.

${ }^{88}$ Danley, cit., págs. 175-176 y 181.

${ }^{89}$ Danley, cit., págs. 176-177.

${ }^{90}$ Charles Taylor, Multiculturalism..., cit., pág. 41.
} 
Porque los comunitarios, desde luego, tienen su propia solución para el problema. Ellos son sin duda partidarios de las cuotas, de modo de garantizar los derechos de los grupos reservando para ellos una porción de los cargos en el Gobierno, negocios y universidades $^{91}$. Si la mayoría de los jueces de la Corte Suprema de los Estados Unidos hubiera adherido al comunitarismo Bakke hubiera perdido su caso frente a la Facultad de Medicina de la Universidad de California ${ }^{92}$, puesto que el individuo de raza negra que había ingresado en su lugar, y con peores calificaciones, hubiera tenido su puesto asegurado en virtud de su pertenencia a una raza determinada. McDonald está interesado en defender los derechos grupales, por ejemplo, puesto que cree que los intereses del grupo no son separables en intereses individuales: ninguno de los miembros del grupo actúa simplemente por sí mismo, sino que cada uno juega su parte en el entendimiento normativo compartido ${ }^{93}$. Pero si esta actuación colectiva depende de que todos los integrantes del grupo se identifiquen con una forma de vida, no debe olvidarse que dos personas que comparten, sin embargo, sus fines y proyectos: los planes de vida de un franco canadiense que desea servir a Dios y el de otro franco canadiense que es ateo son planes de vida que revelan un conflicto entre ellos o -al menos- no son planes de vida compartidos, aunque ambos individuos participen de la cultura franco canadiense ${ }^{94}$.

Los derechos grupales que los comunitarios apoyan se manifiestan típicamente en la propiedad de la tierra ya que ellos sostienen que, en los casos de muchas tribus aborígenes, ese derecho de propiedad debe otorgarse a las comunidades y no a los individuos ${ }^{95}$. Si no se apela al derecho comunitario, de todos modos el derecho de propiedad sobre la tierra que se propone como solución implica que éste se otorga de un modo limitado, con la propiedad ligada durante varias generaciones, de modo que el propietario presente no puede tratada como si fuera su dueño absoluto ${ }^{96}$.

De modo que la existencia presente y futura de diversas culturas se ha querido proteger con derechos comunitarios tanto desde la teoría liberal cuanto desde la propia teoría comunitaria. Sin embargo, no es ésta la única solución posible al problema de la subsistencia de estos grupos, como ahora veremos.

${ }^{91}$ Glazer, cit., pág. 91.

${ }^{92}$ Regents of the University of California v. Allan Bakke, U.S. 98 S. Ct. 2733, 46 LW 4896 (1978).

${ }^{93}$ McDonald, «Should Communities Have Rights?», cit., pág. 218.

${ }^{94}$ Kymlicka, Liberalism, Community, and Culture, cit., pág. 239.

${ }^{95}$ Thompson, cit., pág. 328.

${ }^{96}$ Bigelow, Pargetter y Young, cit., pág. 344. 


\section{Una solución que no apela explícitamente a derechos comunitarios}

Los mismos autores comunitarios sugieren a veces, de manera implícita, una nueva manera de resolver el problema de los grupos minoritarios. Los derechos por los que ellos ahogan tienden a establecer un espacio dentro del cual predominan las reglas del grupo respecto de temas tan específicos como los de la educación, las comunicaciones y la forma de las instituciones políticas ${ }^{97}$. Pero en este caso ese grupo dejaría de ser minoritario y pasaría a constituir un nuevo estado, con su propio ordenamiento jurídico. Esta solución, entonces, está limitada a aquellas minorías que ocupan un territorio determinado, como ocurre con los aborígenes del Canadá.

Un sistema similar se ha propuesto en Australia, donde para formular una concepción de derechos sobre la tierra que resulte adecuada a sus necesidades los aborígenes han reclamado su soberanía, la que no pueden ejercitar mientras sigan siendo ciudadanos de Australia ${ }^{98}$. Es también el método seguido en los Estados Unidos, donde los miembros de las comunidades indias -mediante el sistema de reservas indígenas- han sido capaces de proteger su cultura. Las reservas constituyen jurisdicciones políticas especiales respecto de las cuales las comunidades indias tienen ciertos poderes garantizados ${ }^{99}$.

Esta solución reduce el aire paradójico que rodea a la idea de Raz de que ciertos bienes colectivos no pueden protegerse mediante la concesión de derechos individuales. El derecho de los palestinos a su autodeterminación es difícil de alcanzar otorgando derechos individuales a Arafat respecto de la autodeterminación ${ }^{100}$. Pero la preservación de la cultura palestina si se resuelve -como ya lo advirtió la comunidad internacional- mediante la creación de un estado palestino.

La creación de un nuevo estado atenúa el problema central de los llamados derechos comunitarios, que consiste en su marcada desigualdad. Si las tribus aborígenes se consideraran estrictamente como parte de los Estados Unidos no podría aceptarse que en ellas no se permitiera la libertad de culto. Como no son parte estricta de los Estados Unidos, y los integrantes de las tribus desean un siste-

${ }^{97}$ McDonald, «Liberalism, Community and Culture», cit., págs. 124-125.

${ }^{98}$ Thompson, cit., pág. 328.

${ }^{99}$ Kymlicka, Liberalism, Community and Culture, cit., pág. 136.

${ }^{100}$ Joseph Raz, The Morality of Freedom, Oxford, Clarendon Press, 1986, pág. 136. De todos modos, si la auto-determinación se considera un bien público debo recordar que no es necesario resolver el problema de los bienes públicos otorgando derechos comunitarios. 
ma jurídico de ese tipo, la dificultad se reduce (aunque no desaparece, salvo en el caso de que todos los habitantes de la reserva desean practicar el mismo culto, y no aparezca nunca ningún inmigrante que discrepe). Si la tribu de los inúes no formara parte estricta del Canadá podría ser razonable que estipulara ciertos requisitos para la aceptación de inmigrantes (entre los que podría contarse la práctica de un determinado culto). Como forman parte del estado canadiense, en cambio, no se comprende la manera en que ellos podrían limitar la libertad de tránsito de sus conciudadanos.

Como he dicho antes, no todas las culturas pueden beneficiarse de esta solución. Los portorriqueños viven en New York no disponen de un territorio en el que puedan aplicar sus propias formas jurídicas y constituir un nuevo estado: viven dispersos entre los ciudadanos norteamericanos que habitan allí. Pero donde la solución puede aplicarse ella parece preferible a la que los comunitarios proponen.

\section{El funcionamiento de los derechos comunitarios}

Hasta ahora parece que me he limitado a criticar ciertas deficiencias prácticas en la aplicación de los derechos comunitarios y que éste es el límite de mi objeción a ellos. No es cierto, sin embargo. Mi objeción es mucho más fuerte: creo que los llamados derechos comunitarios no son sino el modo en que se describe cierta restricción de los derechos individuales. Cuando se habla de derechos comunitarios lo que quiere decirse es que algunos derechos individuales han sido restringidos, y nada más que esto.

Abundan los ejemplos de lo que acabo de afirmar. A veces se enuncia expresamente que las metas colectivas pueden requerir ciertas restricciones al comportamiento de los individuos, y que esas restricciones pueden -a su vez- violar derechos de los individuos ${ }^{101}$. $\mathrm{O}$ se sostiene que es mejor que los ingresos comunitarios sean protegidos por la comunidad, puesto que los riesgos para tales intereses se incrementarían si los miembros de la comunidad pudieran ejercer ciertos derechos ${ }^{102}$.

Tampoco faltan casos concretos de estas restricciones. Los comunitarios socialistas sugieren eliminar algunos derechos liberales en aquellas áreas en las que ciertas formas de cultura privada amenazan con tener un impacto destructivo en la cultura pública ${ }^{103}$.

${ }^{101}$ Charles Taylor, Multiculturalism..., cit., pág. 55.

${ }^{102}$ McDonald, «Should Communities Have Rights?», cit., pág. 232.

${ }^{103}$ Miller, «In What Sense..», cit., pág. 72. 
También proponen restringir la actividad de los partidos políticos locales, exigiendo que todos los partidos presenten candidatos en un cierto número de áreas geográficas antes de que sus representantes puedan ser elegidos ${ }^{104}$.

El gobierno de Quebec -como hemos visto- restringe el derecho de sus habitantes a enviar a sus hijos a escuelas anglo-parlantes, y el derecho de sus grandes empresarios a dirigir sus empresas en otro idioma que el francés ${ }^{105}$. Y se han defendido estas restricciones argumentando que una sociedad como la de Quebec no puede sino dedicarse a la defensa y promoción de la cultura y el lenguaje franceses, aunque esto implique cierta restricción de las libertades individuales ${ }^{106}$.

Es común insinuar, por otra parte, que los trabajadores extranjeros deben votar únicamente en las elecciones municipales, $\mathrm{y}$ no en las generales ${ }^{107}$. $\mathrm{O}$ abogar por restricciones a la movilidad sobre la base de que un mundo de movilidad completa sería un mundo de individuos desarraigados ${ }^{108}$.

Pero es ciertamente en el caso de los aborígenes donde mejor se aprecia este rasgo restrictor de los supuestos derechos comunitarios. Para proteger a estas comunidades se han propuesto medidas tales como restringir la movilidad, propiedad y derechos de voto de los individuos no aborígenes, así como su derecho de residencia. Los líderes aborígenes pretenden una residencia de tres años antes de permitir el ejercicio del derecho de voto, un $30 \%$ obligatorio de representación aborigen en el gobierno regional, y un poder de veto en manos de esos representantes sobre aquella legislación que afecte intereses aborígenes cruciales $^{109}$.

Hablar de derechos comunitarios, entonces, es utilizar una forma de expresión que esconde la realidad. Todos los ejemplos de supuestos derechos comunitarios que he mostrado consisten sólo en la restricción de los derechos individuales de los individuos que no integran el grupo protegido. Si el grupo protegido -como suele ocurrir- es una minoría, los derechos comunitarios son disfraces que encubren la restricción de los derechos individuales de la mayoría.

Es muy extraño, entonces, que se haya pasado por alto el costo de imponer estos supuestos derechos comunitarios. Que se olvide

${ }^{104}$ Miller, «Socialism and Toleration», cit., pág. 251.

${ }^{105}$ Charles Taylor, Multiculturalism..., cit., págs. 52-53.

${ }^{106}$ Charles Taylor, «Cross-Purposes: The Liberal-Communitarian Debate», en Nancy Rosenblum(ed.), Liberalism and the Moral Life, cit., pág. 182.

${ }^{107}$ Fullinwider, cit., pág. 269.

${ }^{108}$ Walzer. Spheres of Justice, cit., pág. 39.

${ }^{109}$ Kymlicka, Liberalism, Community, and Culture, cit., págs. 138 y 146-147. 
que las protecciones especiales para las culturas minoritarias resultan en una distribución desigual de derechos ${ }^{110}$ y que no se preste atención a las pérdidas que resultan de adoptar políticas anti-individualistas ${ }^{111}$. La actitud de muchos individuos frente a la eventual protección de ciertas culturas sin duda variaría si se concibe el problema no como uno de conceder derechos a esos grupos, sino como el de restringir los derechos de todos los integrantes de los demás grupos.

Y no se piense -equivocadamente- que éste es un problema lejano que sólo afecta a aquellos vinculados de alguna manera con los inúes, por ejemplo. Cualquiera de nosotros puede verse afectado por la invocación de derechos comunitarios, como lo descubrieron -a su pesar- seis estudiantes norteamericanos que alquilaron una casa en la pequeña localidad de Belle Terre, Long Island. Para preservar el estilo de vida de la comunidad el municipio prohibía que más de dos personas que no tuvieran vínculos de sangre vivieran juntas y la Corte Suprema ${ }^{12}$ sostuvo la constitucionalidad de la ordenanza municipal en cuestión. Disintió el juez Marshall, quien trajo a colación el problema central de invocar derechos comunitarios: esas ordenanzas municipales no podían infringir derechos constitucionales básicos.

\section{Las relaciones entre las comunidades}

Creo que el problema se aprecia con más claridad si observamos las distintas maneras en que puede operar la relación entre dos comunidades (llamémoslas A y B).

Un primer supuesto posible es que ambas comunidades convivan en territorios vecinos, o en un mismo territorio, sin deseos de conectarse mutuamente. Los indios matacos que habitan el norte de la Argentina -por ejemplo- no desean conectarse con el resto de los argentinos ni adoptar sus pautas culturales (conducta que es reflejada exactamente en la actitud del resto de los argentinos frente a los matacos).

Un segundo puesto posible es que la comunidad A desee conec-

${ }^{110}$ Danley, cit., pág. 175.

${ }^{111}$ Kateb, cit., pág. 185.

112 Village of Belle Terre v. Boraas, 416 U.S. 1 (1974). De todas maneras es justo recordar que la Corte Suprema norteamericana declaró inconstitucional una ordenanza municipal que prohibía a los negros adquirir propiedad inmueble en un área residencial blanca (Buchanan v. Warley, 245 U.S. 60 (1917). 
tarse con la comunidad $\mathrm{B}$, infiltrándola ${ }^{113}$ y que la comunidad $\mathrm{B}$ no tenga ningún inconveniente con este propósito. El mestizaje brasileño es el fruto de esta actitud, donde A representa a los negros y primitivos y $\mathrm{B}$ a los blancos primitivos. En ninguno de estos supuestos se requiere ninguno de los llamados derechos comunitarios.

Un tercer supuesto posible lo constituye el caso de la comunidad minoritaria A que desea infiltrar a la comunidad mayoritaria B, la que a su vez no desea que la infiltración se produzca. Es el caso de los negros norteamericanos (A) que deseaban vivir, trabajar y estudiar de la misma manera en que lo hacían los blancos norteamericanos (B). En este supuesto, como lo muestra la historia reciente, basta con otorgar derechos individuales a los integrantes de $\mathrm{B}$ o -mejor dicho- en otorgar a los integrantes de $\mathrm{B}$ los mismos derechos individuales de los que antes sólo disfrutaban los integrantes de A. Ésta es la solución adoptada en Brown vs. Board of Education que mencioné al comienzo de este trabajo.

Un cuarto supuesto posible lo constituye el de una comunidad mayoritaria A que desea infiltrar a la comunidad minoritaria $B$, la que a su vez no desea que la infiltración se produzca. Es el caso de los negros sudafricanos (A) que desean vivir, trabajar y estudiar de la misma manera en que lo hacen los blancos sudafricanos (B). Tampoco en este caso se requieren derechos comunitarios, desde luego. La única diferencia entre este supuesto y el anterior consiste en que aquí la comunidad A es mayoritaria, lo cual -en todo caso sería un argumento más para otorgar a sus integrantes los derechos de los que ya gozan los integrantes de B.

En realidad, y para su desgracia, los aborígenes canadienses que piden la concesión de derechos comunitarios para proteger su cultura frente a los blancos franco y anglo-parlantes se parecen mucho a los blancos sudafricanos que pedían que se mantuvieran sus derechos comunitarios para proteger su cultura respecto de los negros. Tal como lo he mostrado antes, esos derechos comunitarios consistían sólo en restringir los derechos individuales de los sudafricanos negros.

Puede decirse que el resultado final del multiculturalismo contemporáneo no difiere del sistema de privilegio y separatismo que apoyaban los conservadores autoritarios de Sudáfrica ${ }^{114}$.

${ }^{113}$ No hay ninguna connotación peyorativa en la palabra «infiltrar». Sólo deseo describir el caso de una comunidad que desea adoptar el modo de vida de otra, manteniéndose en estrecho contacto con otra.

${ }^{114}$ Gray, cit., pág. 266. 
Acepto que hay diferencias entre las dos situaciones, pero son diferencias sólo graduales. Los inúes llegaron al norte de Canadá antes que los ingleses y los franceses lo hicieran, lo que no fue el caso de los blancos sudafricanos. Los inúes no demandan tampoco el $87 \%$ de la tierra de Canadá ni el derecho de restringir al $84 \%$ de la población canadiense al uso del $13 \%$ de la tierra, como pretendían en cambio algunos sudafricanos blancos respecto de los negros ${ }^{115}$. Pero estas diferencias no constituyen un motivo para otorgar estos supuestos derechos comunitarios a los inúes (ni mucho menos entonces, a los blancos sudafricanos).

El reconocimiento de un nuevo estado atenúa el problema de la desigualdad de derechos entre los habitantes, como he señalado antes. Es posible que el nuevo estado, sin embargo, no otorgue -o no otorgue todos- los derechos individuales propios del estado liberal. Que limite la propiedad de la tierra a la propiedad colectiva, o que restrinja la libertad de los cultos, por ejemplo. ¿Es ésta una objeción para que los liberales acepten la formación de este estado? Yo creo que no es -en todo caso- una objeción decisiva. Los liberales aceptan que se formulen y se lleven a cabo los planes de vida más diversos, entre ellos -desde luego- el plan de vida de vivir como un aborigen. Los rasgos más característicos del comunitarismo que expuse al comienzo ayudan a entender los motivos por los que un aborigen acepta esta restricción de sus derechos. Si la comunidad es al menos parcialmente constitutiva de la identidad del individuo, él aceptará que allí se practique sólo el culto comunitario, como una manera de preservar su identidad. Y si tiene fuertes lazos fraternales con el resto de los miembros de la comunidad, el individuo aceptará la fuerte redistribución del ingreso que implica la propiedad colectiva. El liberal lamentará la forma en que el nuevo estado se ha organizado, pero él no limita su tolerancia a los estados liberales, y reconocerá que los habitantes del nuevo estado han aceptado voluntariamente las restricciones impuestas. Mientras tanto, los derechos individuales de los habitantes del viejo estado liberal no habrán sufrido ninguna merma, porque no habrán sido víctima de ese peligroso espejismo que son los supuestos derechos comunitarios. Pero no quiero ocultar la circunstancia de que esta solución tiene rasgos objetables, puesto el que, para que no los tuviera, el régimen político establecido en el nuevo estado debería haberlo sido por unanimidad. En caso contrario, el ciudadano $x$, que vive en el nuevo estado desde antes que

${ }^{115}$ Kymlicka, Liberalism, Community, and Culture. cit., pág. 247. 
éste se formara y practica un culto diferente, perdería el derecho individual a la libertad de cultos de que disfrutaba en el estado anterior, y debería optar entre practicar el culto comunitario o emigrar. Pero mientras existan partidarios del comunitarismo, el liberal estará obligado a elegir el mal menor en materia de restricción a los derechos individuales ${ }^{116}$.

${ }^{116}$ Estoy agradecido a Carlos Rosenkrantz por sus valiosas observaciones sobre este trabajo. 